\title{
Association of Congenital Cystic Pulmonary Airway Malformation with Schizencephaly
}

\author{
D Jegavanthan, WKS Kularatne \\ Department of General Medicine, Teaching Hospital, Kandy, Sri Lanka.
}

\begin{abstract}
Corresponding Author:
Dr. Dhulashiha Jegavanthan

Email: dhulashi22@gmail.com

This is an Open Access article distributed under the terms of the Creative Commons Attribution License (creativecommons.org/ licenses/by/3.0).
\end{abstract}

Received Accepted

Published

March 3, 2017

June 10, 2017

June 30, 2017

\begin{abstract}
Background: Congenital pulmonary airway malformation (CPAM) is a rare congenital abnormality with unknown exact etiology or clear genetic association. It is characterized by failure of bronchial development and localized glandular over growth. Schizencephaly is another condition described as a rare congenital disorder of neuronal migration characterized by developmental malformation of the cerebral cortex characterized by dysmorphic gray matter lined clefts in the cerebral cortex filled with cerebrospinal fluid, extending medially from the subarachnoid space into and continuous with the ipsilateral lateral ventricle. Case Report: We present a rare case of a young lady presenting with an acute chest infection, found to have asymmetry in her body development, the right half of her body was underdeveloped with growth retardation, eventually diagnosed to have both schizencephaly and congenital pulmonary airway malformation. Conclusion: Future detection and description of such cases including presentation and natural history is of pivotal importance since case prevalence is exceedingly rare.
\end{abstract}

Keywords: Cerebral Cortex, Gray Matter, Organogenesis, Respiratory System Abnormalities, Subarachnoid space.

\section{Introduction}

Congenital pulmonary airway malformation (CPAM) is an uncommon congenital malformation of broncho-alveolar system. It is also known as congenital cystic adenomatoid malformation (CCAM). Typically it is diagnosed on prenatal ultrasound, less frequent in children and even less common in adults. Schizencephaly is another rare congenital disorder of abnormal neuronal migration of cerebral cortex during embryonic development. These two different congenital malformations coincidentally diagnosed in the same patient could be explained by a same pathology involving embryonic malformation of central nervous system as well as the broncho-alveolar system or different pathological entities which were incidentally found together. This needs to be further evaluated to find out the possible associations between the two conditions since there are no case reports or evidence available in literature currently.

\section{Case Report}

A 24 year old apparently healthy lady, mother of one child, presented with a history of low grade intermittent fever, dry cough and right sided pleuritic type chest pain for one month duration. She did not have sputum production, hemoptysis or night sweats but had loss of appetite and weight along with generalized malaise for the last one month. There was no contact history of tuberculosis. Her past medical history and surgical histories were uneventful. She attained menarche in her age of 12 years and had regular menstrual cycles. She is having a child who was born by caesarian section with the indication of short primigravida and following that she or her baby did not have any complications.

Her birth history was uneventful and she was born as normal vaginal delivery with no assistance. She did not suffer from prolonged 
hypoxia after birth. She was breast fed without any complications. Later on she was noticed to have a motor developmental delay that she started to walk with support only after the age of two. But her sensory, language and intellectual development were normal for her age.

She is a left dominant person in view of writing and skills. As time progressed, she noticed to have a mild, functionally insignificant weakness of her right upper and lower limbs. Her immunizations were upto date. She was educated up to the age of 16 years and had average school performance. She has two siblings, none of them were affected with similar illness and they were born to non-consanguineous parents. Her examination revealed an asymmetry in her body development, that the right half of her body was underdeveloped with growth retardation [Fig.1]. Her weight was $31 \mathrm{~kg}$ and height was $140 \mathrm{~cm}$ with the BMI of $15.8 \mathrm{~kg} / \mathrm{m}^{2}$.

She was afebrile, mildly pale, not icteric or cyanosed. There was no lymphadenopathy noted. There was grade III clubbing, but no other

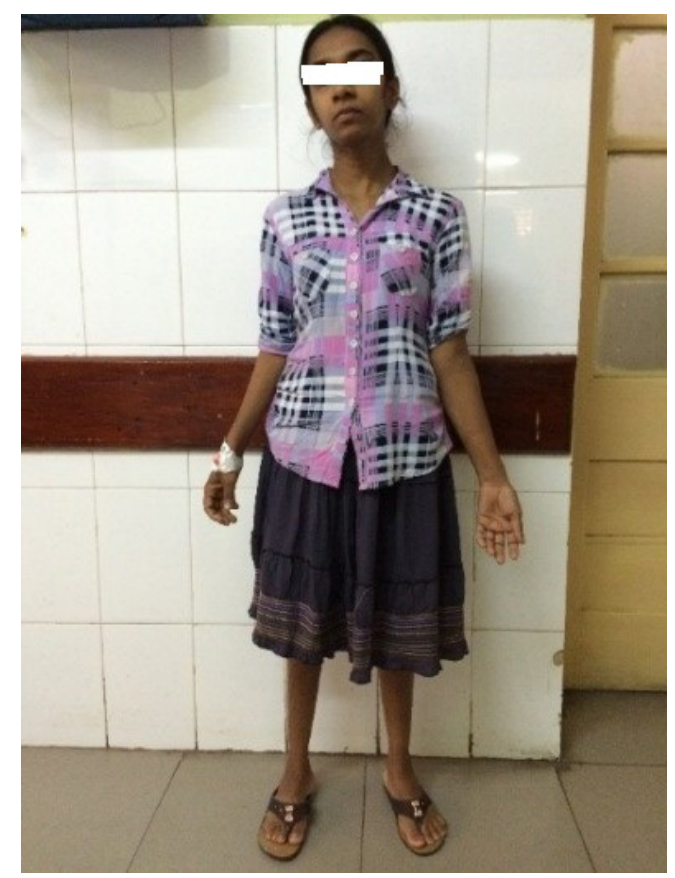

Fig.1: Asymmetry of face and upper limbs. peripheral stigmata of infective endocarditis. Her blood pressure was 130/90 $\mathrm{mmHg}$ with pulse rate of 92 beats/min. She had normal apex in left $5^{\text {th }}$ intercostal space with normal heart sounds and there were no murmurs. On her respiratory examination she was not dyspneic, her respiratory rate was 12 cycles per minute. Trachea was in the center. Her percussion note was dull on right lower zone of lung field with vesicular breathing and there were coarse crepitation's with reduced breath sounds on her right lower zone. There was a mild non-tender firm hepatomegaly with smooth margins however no splenomegaly or ballotable masses. Her limb examinations showed an under developed right sided limbs with increased tone and reflexes with mild reduction in distal muscle power. Plantar responses were equivocal.

Her initial investigations showed normal leucocytes count with neutrophil predominant and normal platelet counts, high ESR of $124 \mathrm{~mm}$ in $1^{\text {st }}$ hour and CRP of $22 \mathrm{mg} / \mathrm{dL}$. Her blood and urine cultures are negative. Chest X-ray showed large cavitatory lesion in right lower lobe with air fluid

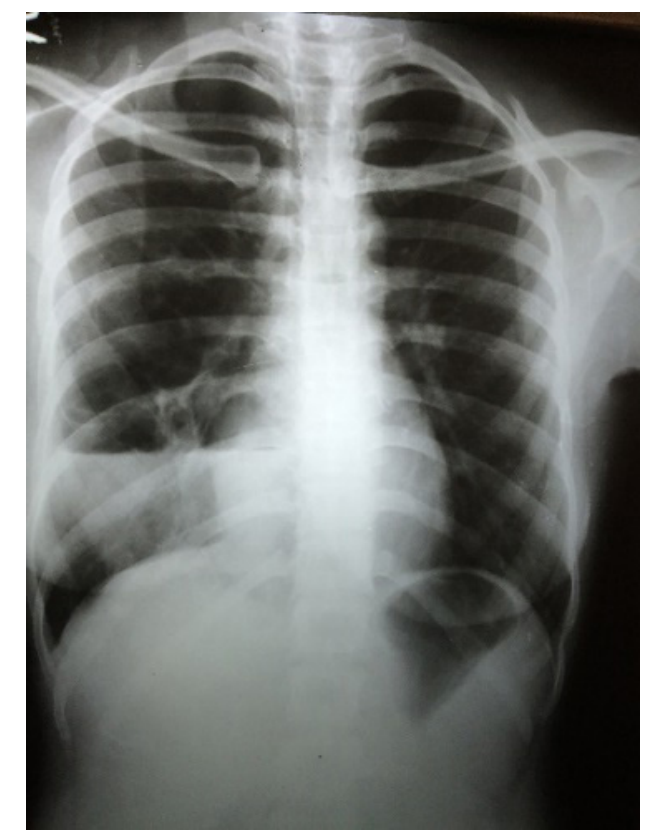

Fig.2: Chest X-ray PA view shows right lower lobe fluid filled cavities with air fluid level. 
level [Fig.2]. Her NCCT brain was suggestive of the diagnosis of left sided schizencephaly [Fig.3]. The CECT chest confirmed multi-locular cystic lesion confined to the right lower lobe. These appearances are highly suggestive of congenital cystic pulmonary airway malformation (CPAM type 1). The fluid level noted within the lesion due to superimposed infection [Fig.4]. Her 2D-ECHO was normal except for a mild mitral valve prolapse. MR imaging of brain being the investigation of choice for diagnosing schizencephaly, the patient was offered with a date for it.

She was managed with intravenous broad spectrum antibiotics according to local antibiotic sensitivity with microbiologist guidance and she improved from the acute lung infection. Later she was counselled regarding her condition and was offered a right lower lobectomy in view of prevention of possible future infection risk and malignant transformation.

\section{Discussion}

Schizencephaly is a rare congenital disorder of central nervous system characterized by the developmental malformation of the cerebral cortex characterized by dysmorphic gray matter lined clefts in the cerebral cortex extending medially from the subarachnoid space into and continuous with the ipsilateral lateral ventricle [1]. It was first described in 1946 in cadaveric specimens by Yakovlev and Wadsworth who coined the name 'Schizencephaly' as congenital clefts in the cerebral mantle [2].

The worldwide prevalence rate is 1.5 in 100,000 live births with no dominance noted in any gender [3]. A specific etiology for the occurrence of schizencephaly is not identified yet. Majority of cases are thought to be sporadic. Various hypotheses have been postulated as causes that it can be associated with the occurrence of neonatal cerebral ischaemia or a stroke during intra-partum or an abnormal neuronal migration due to a genetic mutation although it is yet to be proven. Example

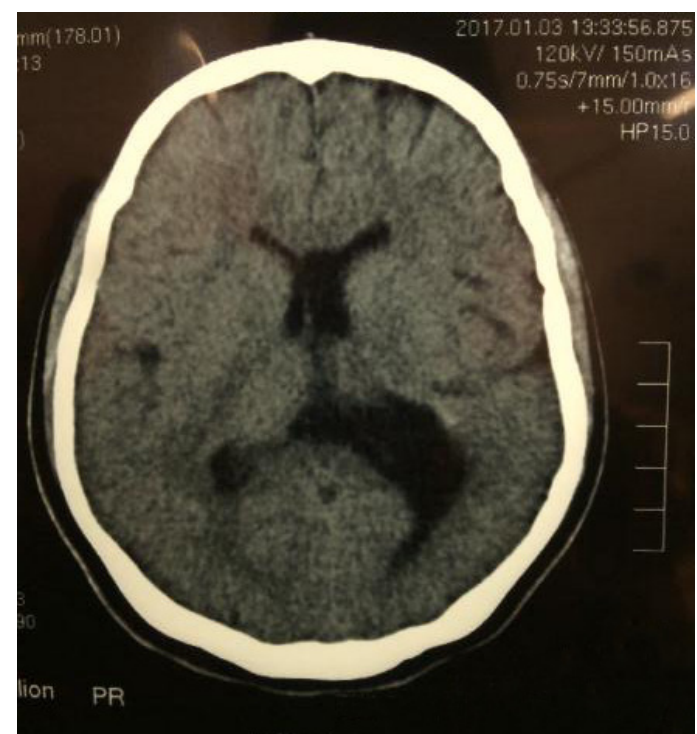

Fig.3: Non-contrast CT brain shows dilated left ventricle and cleft extending into left lateral ventricle from left sylvian fissure suggestive of left sided schizencephaly.

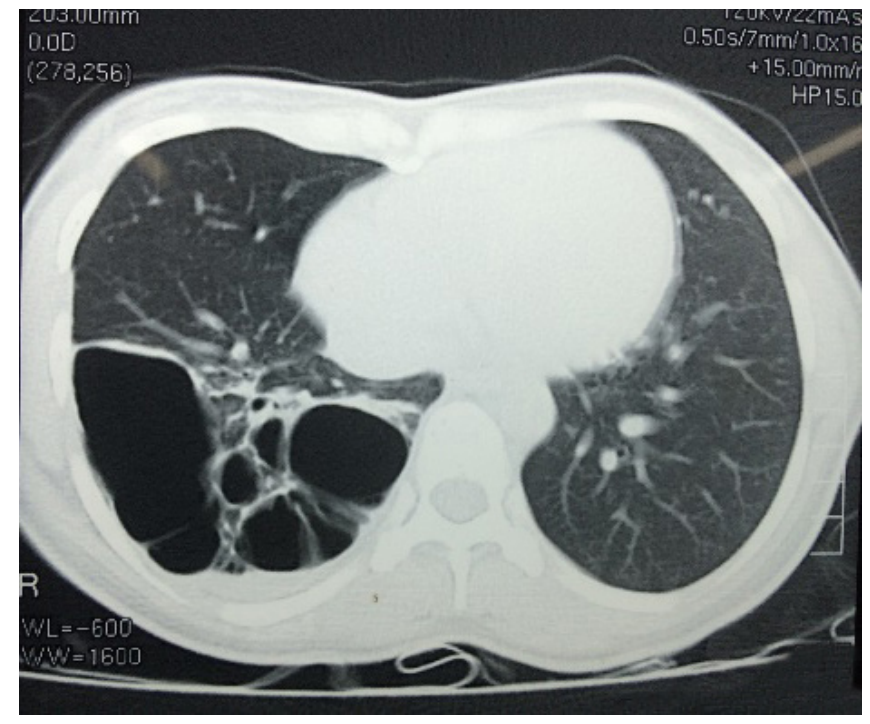

Fig.4: CECT chest showing multiple large air filled thin walled cystic lesions involving upper part of the right lower lobe. Lesion has thin separations and a smaller fluid level. Right hemithorax is smaller as compared to the left side.

given for expression of genetic factors such as the mutant gene is EMX2 [4]. These expressed genetic factors are believed to damage the periventricular germinal matrix impairing cellular migration at 6-7 weeks of intrauterine growth. Another reported case implied a young boy with 
schizencephaly, renovascular hypertension and retinal arteriosclerosis presented with recurrent alveolar haemorrhage. A novel COL4A1 mutation was finally identified as the genetic cause [5]. Although complication or dysfunction of alveolar tissue has not been reported in literature on COL4A1 mutation related disorders it is associated with small vessel dysfunction in brain, kidneys, eyes, muscle and heart. However as in above case our patient also was found to have simultaneous occurrence of schizencephaly and congenital pulmonary airway malformation.

It has been postulated in review articles that schizencephaly cases develop in siblings, pointing towards a probable hereditary and genetic cause. Having a younger or teen age mother is also linked with schizencephaly. An ischaemic stroke developed in utero could be associated with factors such as Cytomegalovirus infections [6], environmental and genetic factors. Schizencephaly is often associated with other congenital abnormalities in 50-90\% of cases [3] such as agenesis of the septum pellucidum and corpus callosum, polymicrogyria, pachygyria, septo optic dysplasia, and optic nerve hypoplasia. Two types of schizencephaly have been described. Type 1 has small symmetrical clefts and the edges of the clefts are fused. Type 2 has extensive clefts that extend from the ventricle to the surface of the brain and subarachnoid space and the edges are not fused. It can be either unilateral or bilateral. Our patient was observed with unilateral type 1 schizenchephaly.

Patients with closed-lip schizencephaly usually present with hemiparesis or motor delay as in our patient, whereas patients with open-lip schizencephaly present with hydrocephalus or seizures [7]. Patients with milder disease might have regular to near average intelligence. Patients with closed-lip and unilateral schizencephaly were more likely to have a mild to moderate outcome than those with open-lip and bilateral type. Also the presentation and outcome of patients with schizencephaly are quite variable but are related to the extent of cortex involved in the schizencephalic defect [7]. Identification of gray matter lining the cleft is the pathognomonic finding in differentiating schizencephaly from porencephaly; this is best demonstrated on magnetic resonance imaging [8].

Management of both types of schizencephaly is conservative. It predominantly consists of rehabilitation of motor symptoms, mental retardation and the control of seizures. Insertion of ventricular shunts may be indicated in patients with open lip schizencephaly or hydrocephalus. When we focus on congenital pulmonary airway malformations (CPAM), they are the most common congenital lung lesion and it comprises around $25 \%$ of all congenital lung lesions [9]. Available data suggest that CPAM affects 1 in 8000-35,000 live births [10], with an estimated incidence of 1 in 25,000-35,000 pregnancies [11].

CPAM was first described in 1949 by Chin and Tank [12]. It was initially classified into three types in 1977 based on the size and number of the cysts [13]. In 1994, Stocker further expanded the CCAM classification into five categories and renamed as congenital pulmonary airway malformation (CPAM). Classification scheme has been revised in 2002 by Stocker [14] [Table 1].

Almost $44 \%$ of CPAM patients are found to have lower lobe lung lesions, primarily unilateral [15]. Type 1 and type 4 CPAM, which have larger cysts, are difficult to differentiate from cystic pleuro-pulmonary blastoma because of its cystic nature [14]. CPAM is diagnosed by CT scans or MRI of chest. CPAM can be diagnosed prenatally by ultrasonography and is categorized into two groups based on the size of the cysts. Echogenic and solid cysts with diameter $<5 \mathrm{~mm}$ are microcystic lesions and those with one or more cysts with diameter $>5 \mathrm{~mm}$ are macrocystic lesions. For the most part, CPAM presents with acute respiratory distress in neonates and infants, but occasionally it can remain unnoticed until adolescence or later life [15]. 
Table 1: Types of congenital pulmonary airway malformations.

\begin{tabular}{|l|l|l|l|l|l|}
\hline & Type 0 & Type 1 & Type 2 & Type 3 & Type 4 \\
\hline Frequency & $1-3 \%$ & $50-65 \%$ & $20-25 \%$ & $8 \%$ & $10 \%$ \\
\hline Relative frequency & Fifth & Most common & $\begin{array}{l}\text { Second most } \\
\text { common }\end{array}$ & Fourth & Third \\
\hline $\begin{array}{l}\text { Presumed site of } \\
\text { development }\end{array}$ & trachea-bronchial & $\begin{array}{l}\text { bronchial/ } \\
\text { bronchiolar }\end{array}$ & Bronchiolar & $\begin{array}{l}\text { bronchiolar } / \text { alveolar } \\
\text { duct }\end{array}$ & distal acinar \\
\hline Cyst size & $0.5 \mathrm{~cm}$ & 2 to $10 \mathrm{~cm}$ & $<2-2.5 \mathrm{~cm}$ & $<0.2 \mathrm{~cm}$ & Varying, up to 7 cm \\
\hline Risk of malignancy & Not identified & $\begin{array}{l}\text { Bronchiolo- alveolar } \\
\text { Carcinoma }\end{array}$ & Not identified & Not identified & $\begin{array}{l}\text { Pleuro-pulmonary } \\
\text { blastoma }\end{array}$ \\
\hline
\end{tabular}

The most common clinical presentation in adults is recurrent pulmonary infection, pneumothorax, hemoptysis, fever and dyspnea [15]. No specific medical therapies are described for congenital cystic pulmonary airway malformation (CCAM). In case of respiratory distress, management ranges from oxygen supplementation to mechanical ventilation. Antibiotic prophylaxis may be necessary in cases with recurrent pneumonia. Otherwise, no medications are specifically indicated for therapy of CPAM. Fetal surgery should be considered in patients with large CPAMs and in cases complicated by hydrops, in which prognosis is poor. Although the number of adult cases with CPAMs and associated lung cancers are small, most of the available literature support that there is a relationship between the two. Surgical resection provides definitive management of this rare condition and alleviates the malignancy risk. The patients with good post-operative outcome have excellent life expectancy.

CPAM and schizencephaly are two different disorders due to congenital malformations. Even though there were no convincing evidence to explain the pathogenesis of both conditions together, an occurrence of both conditions in a single patient could be explained by the same mutation of genes responsible for embryogenesis of the two involved organs, thus needs further detailed evaluation including gene studies to prove the association.

\section{Conclusion}

Future detection and description of such cases including presentation and natural history is of pivotal importance since case prevalence is exceedingly rare.

Contributors: DJ: manuscript writing, literature search, data collection; WKSK: literature search, manuscript editing. DJ will act as guarantor. Both authors approved the final version of the manuscript.

Funding: None; Competing interests: None stated.

\section{References}

1. Barkovich AJ, Norman D. MR imaging of schizencephaly. AJR American Journal Roentgenol. 1988;150:1391-1396.

2. Yakovlev PI, Wadsworth RC. Schizencephalies; a study of the congenital clefts in the cerebral mantle; clefts with hydrocephalus and lips separated. J Neuropathol Exp Neurol. 1946;5:169-206.

3. Enighe W, Ugboma, Agi, CE. Schizencephaly: A case report and review of literature. Nigerian Postgraduate Medical Journal. 2016;23:38-40.

4. Tietjen I, Erdogan F, Currier S, Apse K, Chang BS, Hill RS, et al. EMX2-independent familial schizencephaly: Clinical and genetic analyses. Am J Med Genet A. 2005;135:166-170.

5. Abe Y, Matsuduka A, Okanari K. et al. A severe pulmonary complication in a patient with COL4A1related disorder: A case report. Eur J Med Genet. (2016), http://dx.doi.org/10.1016/j.ejmg.2016.12.008.

6. Chhetri PK, Raut S. Schizencephaly - A case report. J College Med Sci, Nepal. 2010;6:54-56.

7. Delgado MR, Packard AM, Miller VS. Schizencephaly: correlations of clinical and radiologic features. Neurology. 1997;48:1427-1434. 
8. Denis D, Chateil JF, Brun M, et al. Schizencephaly: Clinical and imaging features in 30 infantile cases. Brain \& Development. 2000;22:475-483.

9. Kaynar A, Tastekin E, Usta, U, et al. Congenital pulmonary airway malformation type 2: a case report with review of the literature. Jpn J Clinical Oncol. 2014;44:278-281.

10. Laberge JM, Flageole H, Pugash D, Khalife S, Blair G, et al. Fetal Diagnosis and Therapies: Outcome of the prenatally diagnosed congenital cystic adenomatoid lung malformation: A Canadian Experience. Fetal Diagn Ther. 2001;16:178-186.

11. Christina MS, Michael DK. Cystic lung disease; seminars in pediatric surgery. 2008;17:2-8.

12. Chin KN, Tang MY. Congenital adenomatoid malformation of one lobe of a lung with general anasarca. Archives of Pathology. 1949;48:221-229.

13. Tastekin E, Usta U, Kaynar A, Ozdemir C, Yalkin O, Ozyilmaz F, et al. Congenital Pulmonary Airway Malformation. Turkish Journal Pathol. 2016;32:200204.

14. Baral D, Adhikari B, Zaccarini D, Dongol RM, Sah B. Congenital Pulmonary Airway Malformation in an Adult Male: A Case Report with Literature Review. Case Reports in Pulmonology. 2015;2015:743452.

15. Tastekin E, Usta U, Kaynar, A, et al. Congenital pulmonary airway malformation type 2: a case report with review of the literature. Japanese Journal Clinical Oncol. 2014;44:278-281. 